\title{
Development of a Neuroprotective Erythropoietin Modified with a Novel Carrier for the Blood-Brain Barrier
}

\author{
Po-Chuan Chiu ${ }^{1} \cdot$ Houng-Chi Liou ${ }^{2} \cdot$ Thai-Yen Ling ${ }^{2} \cdot$ Li-Jiuan Shen ${ }^{1,3,4}$
}

Published online: 6 March 2020

(C) The American Society for Experimental NeuroTherapeutics, Inc. 2020

\begin{abstract}
Extremely high doses of erythropoietin (EPO) has been used for neuroprotection in ischemia-reperfusion brain injury to deliver sufficient amounts of EPO across the blood-brain barrier (BBB); however, harmful outcomes were observed afterward. We aimed to test the ability of HBHAc (heparin-binding haemagglutinin adhesion c), an intracellular delivery peptide for macromolecules, as an EPO carrier across the BBB. The cellular internalization and transcytosis ability of HBHAc-modified EPO (EPO-HBHAc) were evaluated in bEnd.3 cells and in the bEnd.3/CTX TNA2 co-culture BBB model, respectively. Subsequently, the NMDA-induced-toxicity model and ischemia-reperfusion rat model were used to understand the neuronal protective activity of EPO-HBHAc. The biodistribution of EPO-HBHAc was demonstrated in rats by the quantification of EPO-HBHAc in the brain, plasma, and organs by ELISA. Our results demonstrate that EPO-HBHAc exhibited significantly higher cellular internalization in dose- and time-dependent manners and better transcytosis ability than EPO. In addition, the transported EPO-HBHAc in the co-culture transwell system maintained the neuronal protective activity when primary rat cortical neurons underwent NMDA-induced toxicity. The calculated cerebral infarction area of rats treated with EPO-HBHAc was significantly reduced compared to that of rats treated with EPO $(29.9 \pm 7.0 \% v s 48.9 \pm 7.9 \%) 24 \mathrm{~h}$ after occlusion in $3 \mathrm{VO}$ rat experiments. Moreover, the EPO amount in both CSF and damaged cortex from the EPO-HBHAc group was 4.0-fold and 3.0-fold higher than the EPO group, respectively. These results suggest that HBHAc would be a favorable tool for EPO brain delivery and would further extend the clinical applications of EPO in neuroprotection.
\end{abstract}

Keywords Erythropoietin $\cdot$ Stroke $\cdot$ Ischemia-reperfusion injury $\cdot$ Transcytosis $\cdot$ Cell-penetrating peptide

\section{Introduction}

Stroke is one of the major causes of morbidity and mortality worldwide and has also remained the leading cause of death

Electronic supplementary material The online version of this article (https://doi.org/10.1007/s13311-020-00845-2) contains supplementary material, which is available to authorized users.

Li-Jiuan Shen

ljshen@ntu.edu.tw

1 School of Pharmacy, College of Medicine, National Taiwan University, Taipei, Taiwan

2 Department and Graduate Institute of Pharmacology, College of Medicine, National Taiwan University, Taipei, Taiwan

3 Graduate Institute of Clinical Pharmacy, College of Medicine, National Taiwan University, Taipei, Taiwan

4 Department of Pharmacy, National Taiwan University Hospital, Taipei, Taiwan globally in the last 15 years [1]. Ischemic stroke is the most common type of stroke and is also a medical emergency. In this condition, brain neurons are deprived of the necessary glucose and oxygen because of the restricted blood circulation in brain tissues [2]. Most current treatment strategies for ischemic stroke are based on pharmacologic and mechanical thrombolysis, but the well-known injury after reperfusion has been clearly demonstrated in experimental studies and clinical cases [3, 4]. Reperfusion injury plays an important role in the prognosis of ischemic stroke [5]. Therefore, there is an urgent unmet medical need for effective treatment for the alleviation of ischemia-reperfusion injury in stroke patients.

Recombinant human erythropoietin (EPO) is a 165 -amino acid glycoprotein that has been clinically used, mainly for the treatment of different types of anemia, for decades [6,7]. After determining the EPO and EPO receptor (EPO-R) expression in neuronal tissues [8], the neuroprotective activity of EPO has been investigated both in vitro and in vivo [7, 9-12]. However, the limited permeability of the blood-brain barrier (BBB) hinders the application of EPO in central nervous system (CNS)-related 
therapy, such as ischemic stroke. CNS-related therapy required $5000 \mathrm{U} / \mathrm{kg}$ of EPO to elicit neuronal protection in previous preclinical studies [13-16]. In a small scale clinical trial, EPO demonstrated a neuroprotective property in ischemia stroke patients administered 33,000 $\mathrm{U}$ daily for 3 days after the onset of symptoms [17]. In clinical practice, the maximum dose of EPO for anemia in chronic kidney disease should not exceed $720 \mathrm{U} / \mathrm{kg}$ or $10,000 \mathrm{U}$ per week $[18,19]$. However, an extremely high dose of EPO, 120,000 U, was administered to ischemic stroke patients in a randomized, double-blind, placebo-controlled clinical trial in 2009 [20]. A significantly higher mortality rate was observed in the EPO group compared to the placebo group (16.4\% vs $9.0 \%$ ), mainly attributable to intracerebral hemorrhage, brain edema, and thromboembolic events. This trial clearly demonstrated that an extremely high dose of EPO did not improve the therapeutic efficacy, and even raised safety concerns [20]. Hence, enhancing the BBB permeability of EPO might increase its potency for neuroprotection and alleviate the hematopoietic adverse effects.

The BBB hinders $98 \%$ of therapeutic small molecules and nearly $100 \%$ of therapeutic macromolecules from entering the CNS [21]. To overcome the barrier, numerous drug delivery strategies have been developed [22-24]. Cell-penetrating peptide (CPP) modification of a therapeutic agent is one of the approaches for non-invasive CNS drug delivery. CPPs are short sequences of amino acids that have been reported to deliver various cargoes without affecting their activities [25]. HBHAc, a CPP derived from heparin-binding haemagglutinin adhesion of Mycobacterium tuberculosis, has been used to overcome resistance in cancer cells via the intracellular targeted delivery of the macromolecule recombinant arginine deiminase (rADI) [26, 27].

We aim to investigate whether HBHAc could be a potential carrier for protein drug delivery to the CNS because infection of the CNS by Mycobacterium tuberculosis has been reported and might be related to the function of heparin-binding haemagglutinin adhesion [28-30]. In this study, we want to extend the application of HBHAc in enhancing the delivery of EPO to the CNS during ischemia-reperfusion injury. HBHAc-modified EPO (EPO-HBHAc) fusion proteins were generated and in vitro and in vivo studies were performed to demonstrate the increased BBB permeability of EPO-HBHAc compared with that of EPO. The newly designed CPP-based delivery system improved the potency of EPO in neuroprotection in vitro and in vivo.

\section{Materials and Methods}

\section{Materials}

Opti-MEM I reduced serum media, HisPur ${ }^{\mathrm{TM}}$ Ni-NTA resin, granulocyte-macrophage colony-stimulating factor (GM-
CSF), B-27 supplement, and Lipofectamine ${ }^{\circledR} 3000$ reagent were purchased from Thermo Fisher Scientific (Waltham, MA, USA). The Cytotoxicity Detection KitPLUS and EPO 2000 IU (Recormon ${ }^{\circledR}$ ) were purchased from Roche (Mannheim, Germany). The anti-EPO antibody and antimouse IgG-HRP antibody were purchased from Santa Cruz Biotechnology (Dallas, TX, USA). The transwell inserts and the cell culture plates were purchased from Corning (Tewksbury, MA, USA). The Superdex200 Increase 10/300 GL column was purchased from GE Healthcare Life Sciences (Marlborough, MA, USA). Quantikine human erythropoietin kit was purchased from R\&D Systems (Minneapolis, MN, USA). All other chemicals were purchased from SigmaAldrich (St. Louis, MO, USA).

\section{Cell Culture}

CHO-K1 cells were a kind gift of Dr. Lih-Ching Hsu (School of Pharmacy, National Taiwan University, Taiwan) and were maintained in Ham's F12 medium supplemented with $10 \%$ FBS, $50 \mathrm{U} / \mathrm{mL}$ penicillin and $50 \mu \mathrm{g} / \mathrm{mL}$ streptomycin. TF-1 cells were purchased from the Bioresource Collection and Research Center (Hsinchu, Taiwan) and were maintained in RPMI 1640 medium supplemented with 10\% FBS, $50 \mathrm{U} / \mathrm{mL}$ penicillin, $50 \mu \mathrm{g} / \mathrm{mL}$ streptomycin and $2 \mathrm{ng} / \mathrm{mL}$ GM-CSF. The brain endothelial cells (bEnd.3) and the astrocytes (CTX TNA2) were a kind gift of Dr. Yu-Li Lo (Department and Institute of Pharmacology, National Yang-Ming University, Taiwan) and were cultured in high glucose DMEM supplemented with $10 \%$ FBS, $50 \mathrm{U} / \mathrm{mL}$ penicillin, $50 \mu \mathrm{g} / \mathrm{mL}$ streptomycin and $1 \%$ L-glutamine. Primary embryonic rat cortical neuron cells were prepared and maintained in neurobasal medium supplemented with $2 \%$ B-27 supplement, $0.5 \mathrm{mM} \mathrm{L}$ glutamine, $50 \mathrm{U} / \mathrm{mL}$ penicillin and $50 \mu \mathrm{g} / \mathrm{mL}$ streptomycin. All cells were maintained at $37{ }^{\circ} \mathrm{C}$ and $5 \% \mathrm{CO}_{2}$ and were subcultured according to the instructions from the American Type Culture Collection (ATCC).

\section{Plasmid Construction}

The pUC57 EPO, pcDNA3.1(+)EpoAB and pcDNA3.1(+ )EpoAB-HBHAc plasmids were digested with $\mathrm{SacII}$ and $K p n I$. To obtain pcDNA3.1(+)EPO and pcDNA3.1(+)EPOHBHAc, the digested pcDNA3.1(+)EpoAB and digested pcDNA3.1(+)EpoAB-HBHAc, respectively, were ligated to a digested EPO DNA fragment by T4 DNA ligase. A cleavable His-tag was added to the proteins to allow their purification by Ni-NTA affinity chromatography. The DNA sequences of plasmids were confirmed by DNA sequencing on an ABI 3730 xl DNA analyzer (Thermo Fisher Scientific, MA, USA). 


\section{Protein Expression and Purification}

The correct plasmids encoding EPO and EPO-HBHAc were transfected into CHO-K1 cells with Lipofectamine 3000 reagent. For the production of fusion proteins, the $\mathrm{CHO}-\mathrm{K} 1$ cells were seeded into $15-\mathrm{cm}$ dishes, and the supernatant was collected. The aggregates and cell pellets were removed by a $0.22-\mu \mathrm{m}$ filter cup and concentrated by a tangential flow filtration system (Millipore, MA, USA). The concentrated supernatant was mixed with HisPur ${ }^{\mathrm{TM}}$ Ni-NTA Resin, and then the mixture was transferred to a column. The resin was washed with buffer A ( $20 \mathrm{mM}$ sodium phosphate, $300 \mathrm{mM}$ $\mathrm{NaCl}, 30 \mathrm{mM}$ imidazole, $\mathrm{pH}$ 7.4) and eluted with buffer B (20 mM sodium phosphate, $300 \mathrm{mM} \mathrm{NaCl}, 100 \mathrm{mM}$ imidazole, $\mathrm{pH}$ 7.4). Fractions were collected in aliquots of $1 \mathrm{~mL} /$ tube during the elution step. The fractions containing target proteins were collected and further purified by a Superdex 200 Increase 10/300 GL column. The purified recombinant fusion proteins were confirmed by Coomassie blue staining and Western blotting with the EPO antibody. The purities of EPO and EPO-HBHAc were determined by the ratio of the target protein band to all the stained bands in a line on the SDS-PAGE gel.

\section{Erythropoiesis Activity Assay}

To analyze the erythropoiesis activity of EPO and EPOHBHAc, TF-1 cells were washed three times with PBS and suspended in medium at a density of $2 \times 10^{5}$ cells $/ \mathrm{mL}$. The cell suspension was placed in each well of a 96-well plate $(10,000$ cells/well), and medium containing EPO standards, EPO or EPO-HBHAc fusion proteins was then added to each well. After $72 \mathrm{~h}$ incubation, the cell proliferation was analyzed by the CCK- 8 assay. Briefly, the CCK- 8 solution was added to each well and incubated with cells for $3 \mathrm{~h}$, and the colorimetric readings were detected by the PARADIGM Detection Platform (Beckman Coulter, CA, USA) [31].

\section{Cellular Uptake Assay}

Cellular uptake of the modified EPO fusion proteins was examined using the bEnd. 3 cell model. For the dose-dependent cellular uptake study, the bEnd.3 cells were seeded on 12-well plates at a density of $4 \times 10^{5}$ cells/well and incubated overnight. Then, the cells were treated with EPO and EPOHBHAc at the doses of $0.5,1$ and $1.5 \mu \mathrm{g} / \mathrm{mL}$ for $1 \mathrm{~h}$ at $37^{\circ} \mathrm{C}$. For the time-dependent cellular uptake study, the cells were treated with $1 \mu \mathrm{g} / \mathrm{mL}$ EPO and EPO-HBHAc for $0.5,1$, 2 , or $4 \mathrm{~h}$ at $37^{\circ} \mathrm{C}$. After incubation, the cells were washed with $20 \mathrm{mU} / \mathrm{mL}$ heparin in cold PBS twice, and then $50 \mu \mathrm{L}$ of cold lysis buffer was added to each well. The cells were detached from the plate by a cell scraper, and the cell suspension was transferred to tubes. The cell suspension was placed on ice for
30 min and vortexed every few minutes to dissolve materials. Finally, the cell suspension was centrifuged at $13,000 \mathrm{rpm}$ for 30 min at $4{ }^{\circ} \mathrm{C}$. The pellet was discarded, and the supernatant was collected and analyzed by Western blotting with EPO antibody.

\section{Transcytosis Assay}

The process of in vitro BBB model construction is demonstrated in Fig. 1. The CTX TNA2 cells were first seeded onto the abluminal side of the insert and allowed to adhere overnight. The insert was flipped back, and the CTX TNA2 cells were cultured for an additional 2 days. Then, bEnd. 3 cells were seeded onto the luminal side of the insert and cocultured with CTX TNA2 cells. The measurement of the transepithelial electrical resistance (TEER) and the analysis of the paracellular diffusion are widely accepted quantitative techniques to evaluate the integrity of tight junctions in cell culture models [32]. The medium was changed every day, and the TEER value of each well was measured by a Millicell ERS Voltohmmeter (Millipore, MA, USA).

The following experiments were conducted when the TEER value of each insert reached over $200 \Omega * \mathrm{~cm}^{2}$. FITC conjugated dextran was used as a tracer to evaluate the paracellular diffusion of the in vitro BBB model. FITC-70Kdextran was added to the inserts, and the basolateral medium was collected at 3, 6, 12 and $24 \mathrm{~h}$. The fluorescence intensity in the collected medium was measured by the PARADIGM Detection Platform (Beckman Coulter, CA, USA), and the accumulation of FITC-70K-dextran was calculated by the equation $Q n=\sum_{n=1}^{\infty} M n-1 * 0.2+\mathrm{Mn} * 2$ ( $Q$ : accumulated fluorescence intensity; $M$ : measured fluorescence intensity; $n$ : ordinal number of sampling).

To evaluate the transcytosis activity of EPO and EPOHBHAc, $10 \mu \mathrm{g} / \mathrm{mL}$ of these fusion proteins were added to the inserts of the in vitro BBB model. Then, basolateral samples were collected at 3,6,12 and $24 \mathrm{~h}$ and analyzed by Western blotting with the EPO antibody. Subsequently, the conditioned basolateral medium was collected at $24 \mathrm{~h}$, and TF-1 cells and primary rat cortical neurons were incubated with conditioned medium to evaluate the erythropoiesis activity and neuroprotective activity of EPO and EPO-HBHAc after transcytosis, respectively. For the erythropoiesis activity assay, the TF- 1 cells were analyzed by CCK- 8 assay after $72 \mathrm{~h}$ incubation; the detailed process was described in the previous section under erythropoiesis activity assay. For the neuroprotection assay, primary cortical neurons were obtained from rat embryos. The cortices at embryonic day 17 were dissociated and plated onto poly-D-lysine coated 96-well plates at $1 \times 10^{4}$ cells/well. The medium was changed every other day. The neuroprotection assay was started at day 7 after seeding. The 
Seed CTX TNA2 cells

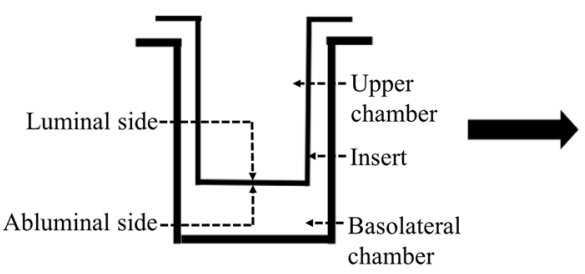

Grow for 2 days

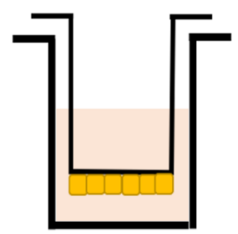

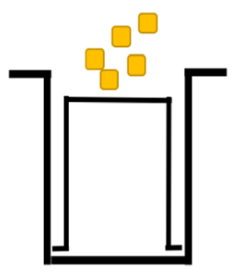

Seed bEnd. 3 cells

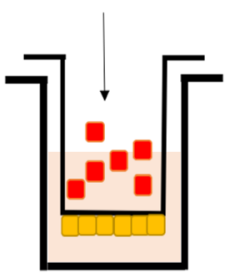

Adhere for overnight

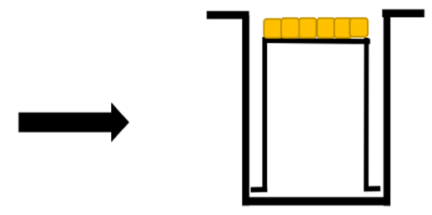

Co-culture for several days

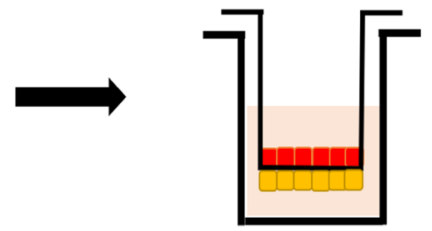

Fig. 1 The construction process of the in vitro BBB model. CTX TNA2 cells were first seeded on the abluminal side of the insert, and bEnd. 3 cells were seeded on the luminal side of the insert. These two cells were co-cultured for several days

NMDA-induced neurotoxicity model was chosen to evaluate the neuroprotective activity of EPO and EPO-HBHAc. The neurons were challenged with $200 \mu \mathrm{M}$ of NMDA for $15 \mathrm{~min}$ and treated with the conditioned medium collected from the basolateral chamber of the in vitro BBB model for an additional $24 \mathrm{~h}$. The cytotoxicity and cell viability were analyzed by the Cytotoxicity Detection KitPLUS and CCK-8 assay kits, respectively. Briefly, for the cytotoxicity detection, the cell supernatant was collected and incubated with the Reaction Mixtures for $30 \mathrm{~min}$, and the absorbance of the samples was measured at $490 \mathrm{~nm}$. The process of the CCK- 8 assay was described previously as the erythropoiesis activity assay.

\section{In Vivo Distribution Study}

All experimental protocols were approved by the National Taiwan University College of Medicine and College of Public Health Institutional Animal Care and Use Committee (IACUC: 20150427). This institution has earned AAALAC accreditation. Male Wistar rats ( 250 to $275 \mathrm{~g}$ ) were used in this study. We used the 3 vessels occlusion (3VO) model to provide consistent focal cortical infarction. The rats were anesthetized by exposure to 1 to $3 \%$ isoflurane, and the fur on the head and neck area was shaved. The two common carotid arteries (CCAs) were occluded by artery clips, and the right middle cerebral artery (MCA) was tied with a 10-0 suture. These procedures were completed within $15 \mathrm{~min}$, and the rats were placed on a thermal blanket to maintain an adequate rectal temperature of $37 \pm 0.5{ }^{\circ} \mathrm{C}$. After an occlusion of $50 \mathrm{~min}$, the artery chips and sutures were removed, and the reflow of the right MCA and two CCAs was determined under a microscope. The common dose of EPO used in previous studies is $5000 \mathrm{U} / \mathrm{kg}$, intraperitoneally, and EPO showed good neuroprotective effect at this dose. The modified EPO delivered into carotid arteries could evade systemic distribution before reaching damaged brain tissues in this study. Thus, the intra-arterial delivery of modified EPO is conducted to observe the brain permeation ability of HBHAc-modified EPO with less interfered factors to prove our concept. On the other hand, considering the greater bioavailability of EPO in brain tissues via direct carotid artery administration, the dose was adjusted to $1000 \mathrm{U} / \mathrm{kg}$. The $3 \mathrm{VO}$ rats were randomly separated into three groups and were treated with vehicle, $1000 \mathrm{U} / \mathrm{kg}$ EPO or $1000 \mathrm{U} / \mathrm{kg}$ EPO-HBHAc proteins through carotid artery infusion at the onset of post-stroke reperfusion. The injected volume and the infusion rate were $200 \mu \mathrm{L} /$ rat and $12 \mathrm{~mL} / \mathrm{h}$, respectively. Cerebrospinal fluid (CSF) and blood samples were collected $3 \mathrm{~h}$ after administration of respective vehicle or protein drugs, and the main organs of each rat were also collected after thorough transcardial perfusion, including the brain, heart, lung, kidney, liver, spleen, and pancreas. The right/left cortex was collected separately. The organs were immediately immersed in liquid nitrogen, homogenized in ice-cold lysis buffer, and then centrifuged to obtain the supernatant. The target proteins in collected samples were analyzed by the Quantikine human erythropoietin kit.

\section{In Vivo Neuroprotection Study}

For the neuroprotection assay, the $3 \mathrm{VO}$ rats were treated with vehicle, $1000 \mathrm{U} / \mathrm{kg}$ EPO, or $1000 \mathrm{U} / \mathrm{kg}$ EPO-HBHAc at the 
onset of reperfusion, and brain infarct evaluations were performed $24 \mathrm{~h}$ after the start of occlusion. The rats were euthanized and the brains were removed and washed with cold normal saline to remove blood. The brain matrix was sliced into six consecutive coronal sections of $2 \mathrm{~mm}$ thickness, and the sections were stained with $2 \%$ 2,3,5-triphenyltetrazolium chloride (TTC) in the dark for $10 \mathrm{~min}$. After staining, the infarct volume was analyzed with ImageJ (National Institutes of Health, MD, USA), and the data are presented as infarct volume as a percentage of contralateral cerebral cortex volume.

\section{Statistics}

Two-tailed Student's $t$ test was used to compare the results between two groups, and one-way ANOVA followed by Bonferroni correction was used to compare three or more groups. Differences were regarded as significant when $p<0.05$.

\section{Results}

\section{Design and Characteristics of Purified EPO Fusion Proteins}

To enhance BBB permeability of EPO, we designed an HBHAc-modified EPO fusion protein. The unmodified EPO protein served as the control. The construction design of unmodified EPO and CPP-modified EPO proteins is shown in Fig. 2A, and the sequences of each plasmid are given in Figure $\mathrm{S} 1$ and $\mathrm{S} 2$. The corrected plasmids expressing EPO and EPO-HBHAc were transfected into $\mathrm{CHO}-\mathrm{K} 1$ cells, and the corresponding proteins were generated and purified. We have successfully constructed EPO and EPO-HBHAc, and both proteins maintained erythropoiesis activity. The purified proteins were analyzed by Coomassie blue staining, and the purity was calculated. As shown in Fig. $2 \mathrm{~B}$ and Table 1, the purities of EPO and EPO-HBHAc were $85.0 \pm 4.8 \%$ and 78.5 $\pm 6.1 \%$, respectively. The purified proteins were further identified by Western blotting with the EPO antibody and showed expected molecular weights corresponding to EPO and EPOHBHAc, respectively (Fig. 2C). TF-1 cells were used to evaluate the erythropoiesis activity of purified EPO and EPOHBHAc, and the specific activities of EPO and EPOHBHAc were $56.7 \pm 21.2 \mathrm{U} / \mu \mathrm{g}$ and $42.4 \pm 11.7 \mathrm{U} / \mu \mathrm{g}$, respectively (Table 1).

\section{Enhanced Cellular Uptake of Brain Endothelial Cells}

EPO-HBHAc showed significantly higher cellular uptake ability compared to EPO in the bEnd.3 cell model in a dosedependent manner at concentrations from 0.5 to $1.5 \mu \mathrm{g} / \mathrm{mL}$ at $37^{\circ} \mathrm{C}$. As shown in Fig. 3A and B, the intensities of the above concentrations were compared to the $0.5 \mu \mathrm{g} / \mathrm{mL}$ EPO-treated group. The EPO groups exhibited intensities of 1-, 2.0-, and 2.2-fold and the EPO-HBHAc groups exhibited intensities of 3.9-, 13.3-, and 21.9-fold, respectively, compared with the $0.5 \mu \mathrm{g} / \mathrm{mL}$ EPO-treated group at the indicated concentrations. Subsequently, a time-dependent study of EPO-HBHAc was performed on bEnd. 3 cells. The cells were treated with the $1 \mu \mathrm{g} / \mathrm{mL}$ of EPO and EPO-HBHAc at the indicated time intervals. The EPO-HBHAc group generally exhibited higher cellular uptake compared to the EPO group, and the results showed that EPO-HBHAc had higher cellular uptake ranging from 2.5-fold to 5.8-fold compared to EPO at the indicated time points (Fig. 3C, D). Additionally, a surge of internalization at the beginning was observed in the EPO-HBHAc group, and the amount of intracellular accumulated EPO-HBHAc increased as the incubation time increased. This result indicates that uptake of EPO-HBHAc by bEnd. 3 cells was related to the incubation period. Taken together, these results demonstrate that cellular uptake of EPO-HBHAc depended on dose and incubation time.

\section{Enhanced Transcytosis Ability in the In Vitro BBB Model}

A suitable in vitro BBB model was established in a CTX TNA2 cell and bEnd. 3 cell co-culture model. The TEER values of the in vitro BBB model were measured every day to evaluate the integrity of the tight junctions. The values continuously increased and reached a plateau at 7 days after bEnd.3 seeding (Fig. 4A). The paracellular diffusion assay was performed when the TEER value over $200 \Omega * \mathrm{~cm}^{2}$. Comparing the fluorescence intensity of the co-culture inserts with the inserts without cell seeding at $24 \mathrm{~h}$, the paracellular diffusion of dextran was significantly blocked in the coculture inserts (Fig. 4B). It was shown that only $2.8 \%$ of $70 \mathrm{~K}$-dextran could move from the upper chamber to the basolateral chamber in co-culture inserts. The restricted paracellular diffusion of 70K-dextran and a sufficient TEER value were clearly demonstrated, and these results indicate that the CTX TNA2 cell and bEnd.3 cell co-culture model had sufficient tight junction integrity to block the transcytosis of macromolecules above a certain molecular weight. This coculture system would be an ideal in vitro BBB model for the investigation of EPO-HBHAc transcytosis under normal condition.

The transcytosis activity of EPO was only a minimally detectable amount; in contrast, EPO-HBHAc demonstrated much higher transcytosis activity than EPO as observed in this in vitro model. As shown in Fig. 5, the accumulated intensity of EPO-HBHAc group was 16.8-fold higher than the EPO group in the basolateral chamber at $24 \mathrm{~h}$. The accumulated intensity could reflect target protein amounts at different time 
a

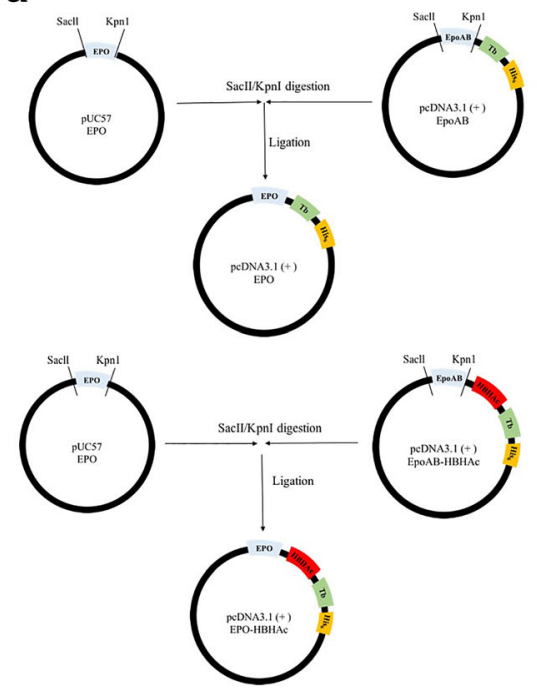

b

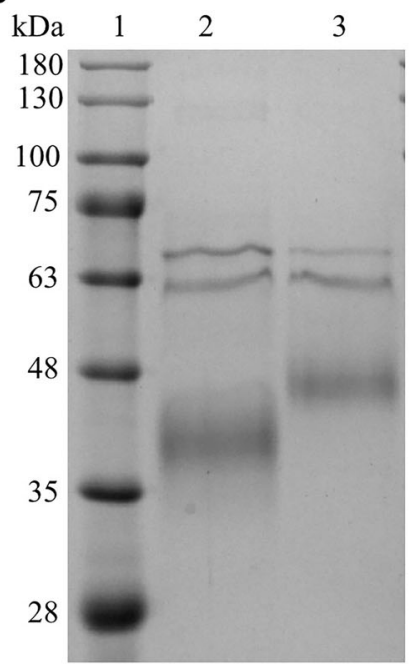

C

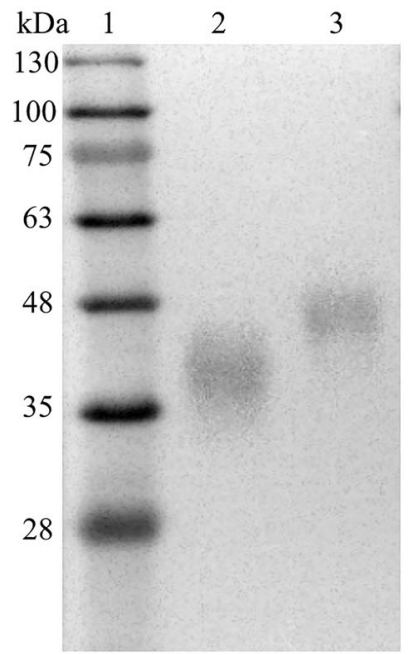

Fig. 2 Design and characteristics of purified EPO and EPO-HBHAc. (A) Plasmid vector encoding EPO was constructed from pUC57 EPO and pcDNA3.1(+) EpoAB vector. Plasmid vector encoding EPO-HBHAc was constructed from pUC57 EPO and pcDNA3.1(+) EpoAB-HBHAc vector. His-tag was added to EPO and EPO-HBHAc for purification purposes. The purified EPO and EPO-HBHAc were identified by (B)

points, and this result indicates that EPO-HBHAc exhibited better transcytosis ability in this in vitro BBB model. In addition, the level of the accumulated transported EPO-HBHAc was also higher than that of EPO in damaged endothelium under oxygen-glucose deprivation (OGD)/reoxygenation (R) condition with similar values of TEER and the amount of transported dextran in this in vitro BBB model (Figure S3). There is no significant protective effect of EPO and EPOHBHAc on damaged endothelium under $\mathrm{OGD} / \mathrm{R}$ in vitro (Figure S4).

\section{Reserved Erythropoiesis Activity and Neuroprotective Activity after Transcytosis through the In Vitro BBB Model}

EPO-HBHAc not only showed strong transcytosis ability from the apical side to the basolateral side in an in vitro BBB model but also maintained better erythropoiesis and neuroprotective activities than EPO. The proteins were dosed in the apical side in the in vitro BBB model for $24 \mathrm{~h}$, and the medium in the basolateral chamber was collected and used as conditioned medium for the following erythropoiesis and

Table 1 The purity and erythropoiesis activity of purified EPO and EPO-HBHAc

\begin{tabular}{|c|c|c|}
\hline & EPO & $\begin{array}{l}\text { EPO- } \\
\text { HBHAc }\end{array}$ \\
\hline Purity (\%) & $85.0 \pm 4.8$ & $78.5 \pm 6.1$ \\
\hline Erythropoiesis activity $(\mathrm{U} / \mu \mathrm{g})$ & $56.7 \pm 21.2$ & $42.4 \pm 11.7$ \\
\hline
\end{tabular}

Coomassie blue staining. (C) Western blot with EPO antibody. The molecular weight of EPO is approximately $35 \mathrm{kDa}$, and HBHAc modification gives EPO-HBHAc a slightly higher molecular weight than EPO. Both EPO and EPO-HBHAc have some impurities at approximately 63 kDa. 1: Protein ladder; 2: EPO; 3: EPO-HBHAc

neuroprotection studies. For the erythropoiesis study, conditioned medium containing transported EPO and EPO-HBHAc induced increases in TF-1 cell proliferation of $102.9 \pm 2.2 \%$ and $132.5 \pm 1.9 \%$, respectively (Fig. 6). For the neuroprotection study, conditioned medium containing transported EPOHBHAc led to statistically significantly higher viable embryonic cortical neurons (Fig. 7A) and reduced cytotoxicity (Fig. 7B) under the NMDA treatment compared to the control and EPO groups $(p<0.05)$.

\section{EPO-HBHAc Improved the BBB-Penetrating Ability and Therapeutic Efficacy In Vivo}

In the $3 \mathrm{VO}$ in vivo model, significantly higher amounts of EPO in both CSF and cortex, as well as reduced infarct volume, were observed in the rats treated with EPO-HBHAc compared to those treated with EPO. The rats were treated with vehicle, EPO or EPO-HBHAc at the onset of reperfusion, and the amount of EPO in CSF, ipsilateral cortex (damaged side), and contralateral cortex was measured $3 \mathrm{~h}$ after dosing. The rats treated with EPO-HBHAc showed a 4.0-fold higher EPO amount in CSF than the EPO-treated rats (Fig. 8A). In addition, the accumulated EPO in ipsilateral cortex and contralateral cortex was also quantified, and protein amounts were $13.3 \pm 2.5 \mathrm{mU} / \mathrm{g}$ (ipsilateral) and $4.0 \pm 1.9 \mathrm{mU} / \mathrm{g}$ (contralateral) in the EPO group and were $40.0 \pm 10.0 \mathrm{mU} / \mathrm{g}$ (ipsilateral) and $10.7 \pm 1.7 \mathrm{mU} / \mathrm{g}$ (contralateral) in the EPOHBHAc group (Fig. 8B). This result indicates that the EPOHBHAc showed better BBB-penetrating ability compared to EPO in both normal and damaged cortices. The amounts of 
$\mathbf{a}_{\mathrm{kDa}}$

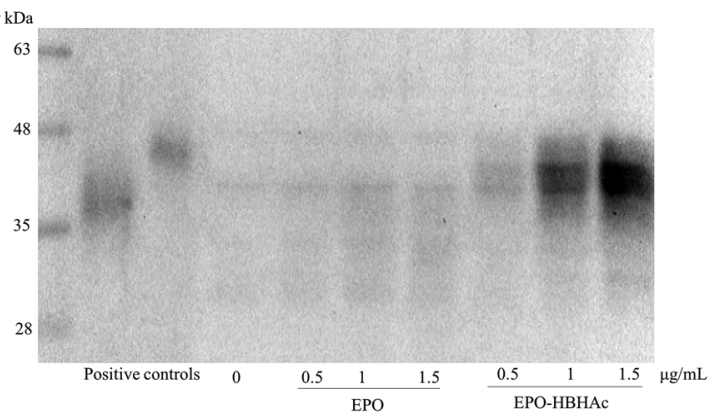

$\mathbf{C}_{\mathrm{kD}}$

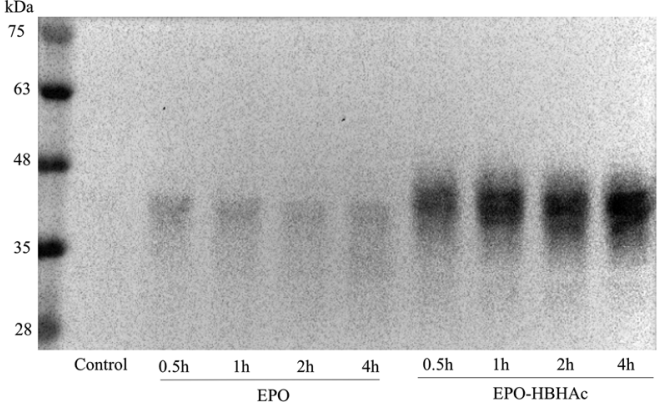

Fig. 3 Dose-dependent and time-dependent cellular uptake study. For the dose-dependent study, bEnd.3 cells were treated with the indicated dose of EPO or EPO-HBHAc. After $1 \mathrm{~h}$ incubation, the target proteins in the cell lysate were detected by Western blotting with the EPO antibody. The same amount of EPO and EPO-HBHAc was used as a positive control. (A) Western blot. (B) Signal intensity in different groups was quantified.
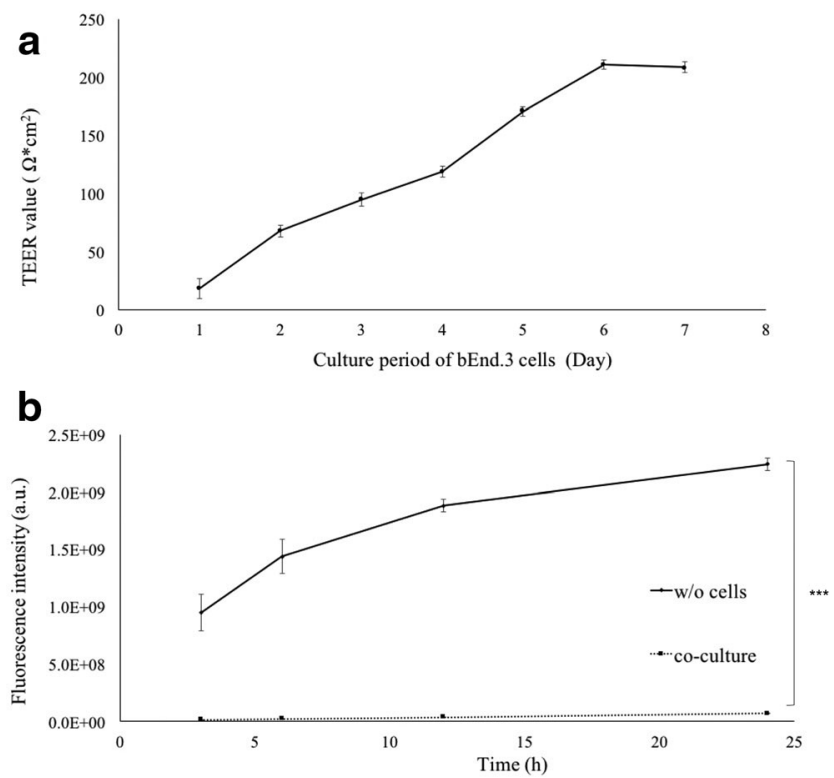

Fig. 4 Evaluation of CTX TNA2 and bEnd. 3 co-culture in the in vitro BBB model. (A) TEER values were measured every day during the coculture period. (B) FITC-70K-dextran was added to the insert after the cells were co-cultured for 7 days, and the medium was collected from the basolateral chamber at 3, 6, 12, and $24 \mathrm{~h}$ after dosing. The fluorescence intensities of collected samples were measured by a fluorescence microplate reader. Data points marked with $* * *$ indicate $p<0.001$. All values are mean $\pm \mathrm{SD}(N=3)$ b

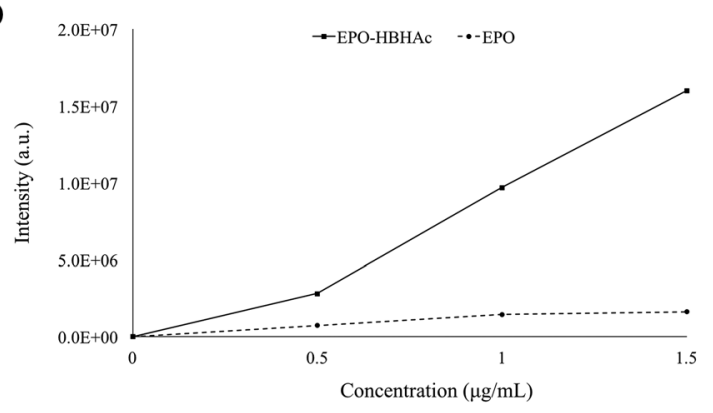

d

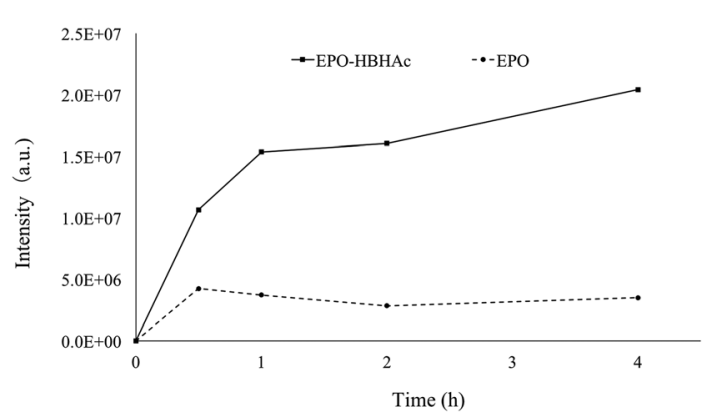

For the time-dependent study, bEnd. 3 cells were treated with $1 \mu \mathrm{g} / \mathrm{mL}$ of EPO or EPO-HBHAc and incubated for $0.5,1,2$ and $4 \mathrm{~h}$. After incubation, the cells were lysed, and the target proteins in the cell lysate were also detected by Western blotting. The intensity at $0 \mathrm{~h}$ was used as a control. (C) Western blot. (D) Signal intensity at different time points was quantified

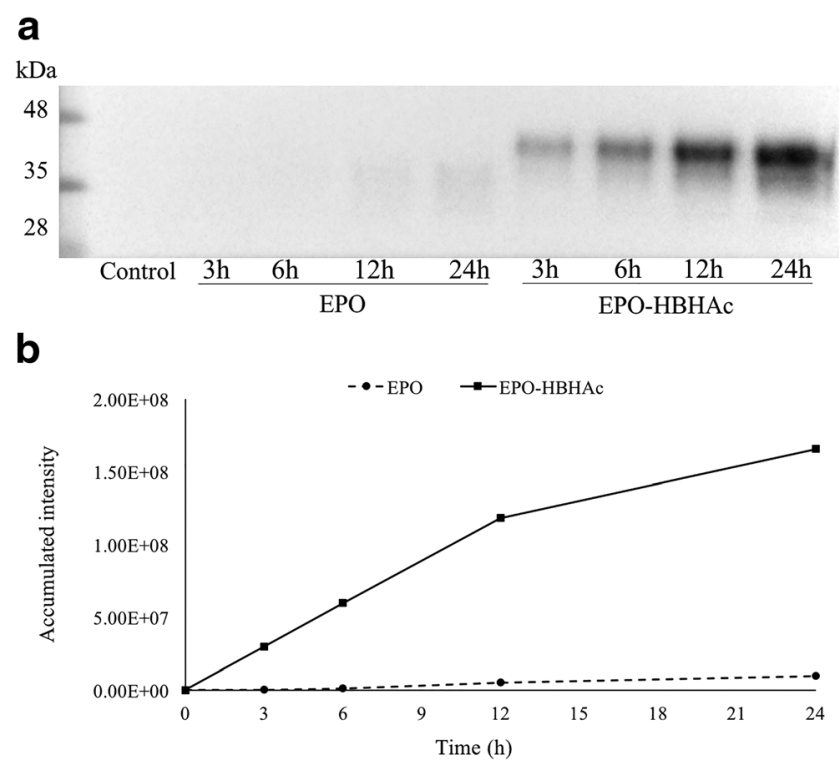

Fig. 5 Transcytosis activity of EPO-HBHAc in the in vitro BBB model. Indicated amounts of EPO and EPO-HBHAc were added to the in vitro BBB model. The samples were collected at $3 \mathrm{~h}, 6 \mathrm{~h}, 12 \mathrm{~h}$ and $24 \mathrm{~h}$ from the basolateral chamber, and the target proteins in collected samples were detected by western blotting with EPO antibody. The arbitrary intensity at $0 \mathrm{~h}$ was used as the control. (A) Western blot. (B) The accumulated intensity was calculated and represented the accumulated amount of target proteins 


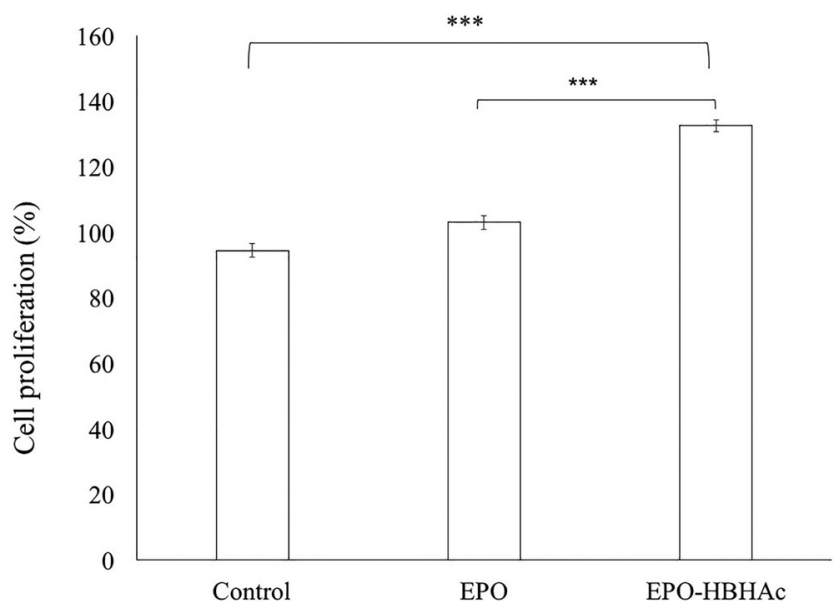

Fig. 6 Evaluation of the erythropoiesis activity of EPO fusion proteins after transcytosis through the in vitro BBB model. TF-1 cells were incubated with the conditioned medium collected from the basolateral chamber of the in vitro BBB model for $72 \mathrm{~h}$. The cell proliferation was measured by the CCK-8 assay. Data points marked with $* * *$ indicate $p<$ 0.001 . All values are mean $\pm \mathrm{SD}(N=3)$

EPO in other organs and plasma were not statistically different between the EPO group and the EPO-HBHAc group (Figure S5 and S6).

Evans blue was used to assess the BBB permeability of $3 \mathrm{VO}$ rats, and the ratios of Evans blue in ipsilateral to contralateral cortex were $3.86 \pm 1.74,5.27 \pm 2.07$, and $4.06 \pm 2.16$ in control, EPO, and EPO-HBHAc groups, respectively (Figure S7). This result indicates that both EPO and EPOHBHAc did not exacerbate the BBB permeability.

Subsequently, to evaluate cerebral infarction, the rats received EPO or EPO-HBHAc at the onset of reperfusion. The brains were stained with TTC reagent $24 \mathrm{~h}$ after $3 \mathrm{VO}$; the white color indicates the infarction region while the noninfarct region is colored red in the brain slices (Fig. 9A). As shown in Fig. 9B, the ratio of infarct volume was represented as a percentage of the contralateral region of the cortex. The infarct volumes in the control group, EPO group, and EPOHBHAc group were $68.0 \pm 5.7 \%, 48.9 \pm 7.9 \%$, and $29.9 \pm$ $7.0 \%$, respectively. $3 \mathrm{VO}$ caused a consistent infarct volume in this study within the acceptable variations between each animal. The EPO group and EPO-HBHAc group both significantly reduced the infarct volume compared to the control group. In addition, EPO-HBHAc elicited an even better effect on reducing the cerebral infarction than EPO.

\section{Discussion}

The effective delivery of therapeutic molecules to the CNS is a challenge due to low BBB permeability of these therapeutic agents. To deliver macromolecules, such as protein drugs, the permeability of the BBB is an even greater obstacle. EPO is a potential drug for ischemic stroke, but unwanted a

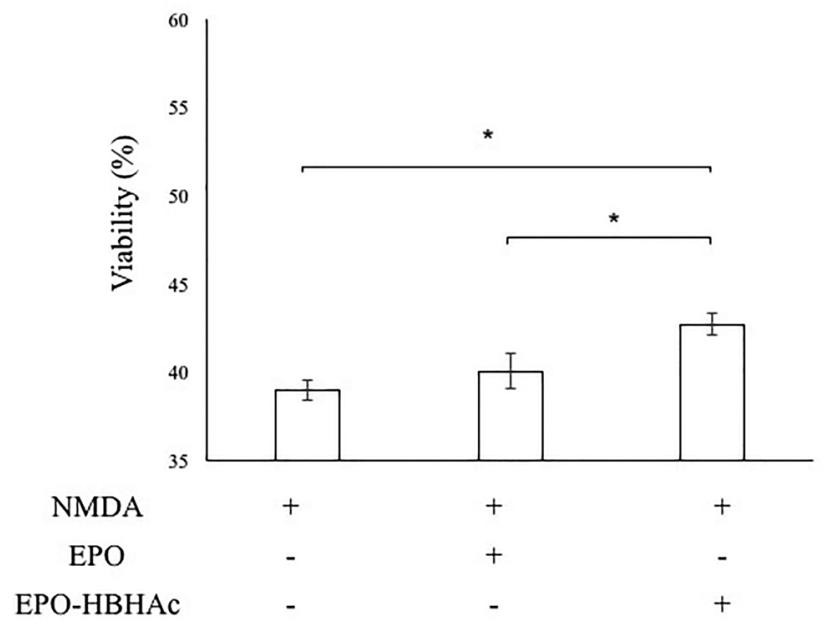

b

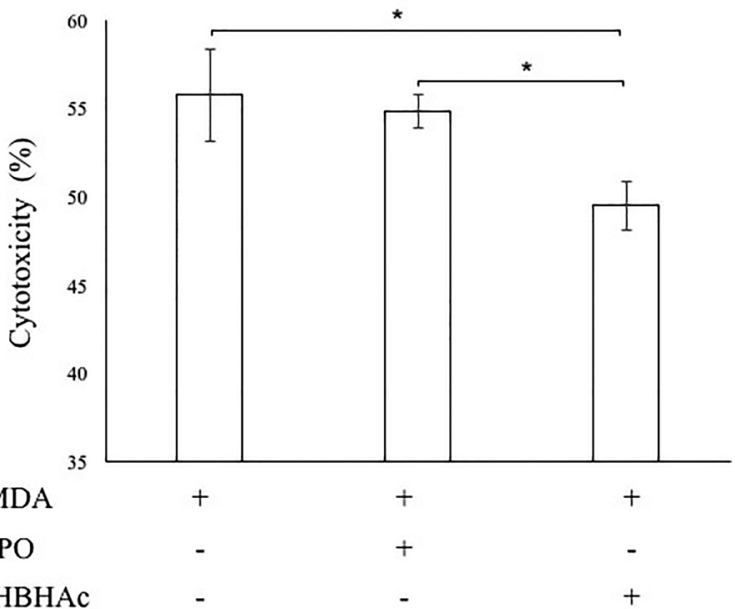

Fig. 7 Evaluation of neuroprotective activity of EPO fusion proteins after penetrating through the in vitro $\mathrm{BBB}$ model. After the induction of cytotoxicity by NMDA, the rat embryonic cortical neurons were treated with conditioned medium collected from the basolateral chamber of the in vitro $\mathrm{BBB}$ model for an additional $24 \mathrm{~h}$. The viability (A) and cytotoxicity (B) were measured by CCK-8 and Cytotoxicity Detection KitPLUS reagents, respectively. Data points marked with $*$ indicate $p<0.05$. All values are mean $\pm \mathrm{SD}(N=3)$

hematopoietic adverse events were reported when stroke patients were treated with high-dose EPO [33]. Numerous recent studies were devoted to overcoming the BBB and successfully delivering drugs into the brain, and there has been an increasing interest in using CPPs for brain delivery of therapeutic molecules [34, 35]. In addition, there are limited approaches for EPO CNS delivery, such as intranasal delivery [36], CPP (TAT was the earliest reported CPP) [37], monoclonal antibody modification of EPO [38], and BBB disruption by focused ultrasound [39]. Unlike the previous studies on CPPmodified EPO, our study is the first to evaluate both the therapeutic efficacy and biodistribution of CPP-modified EPO in an ischemia-reperfusion model. EPO-HBHAc was generated 
a

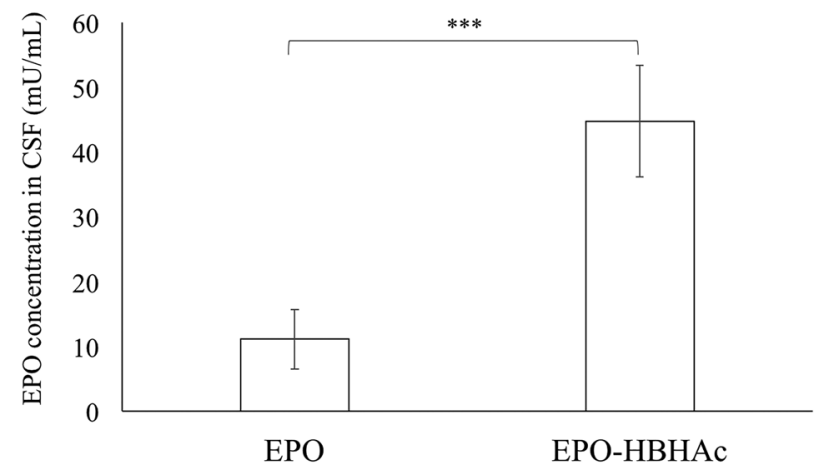

b

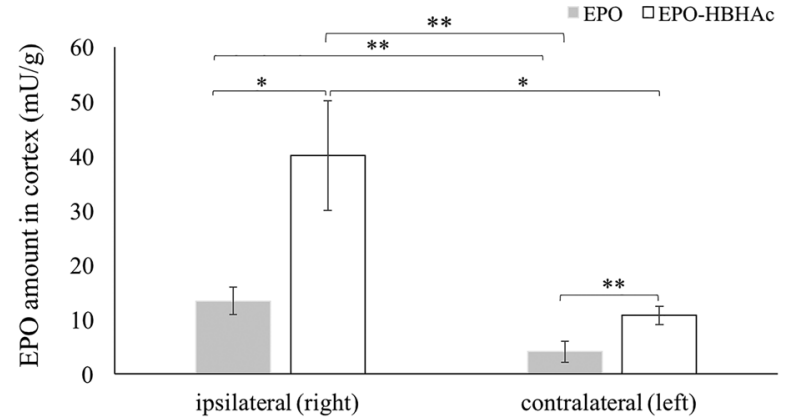

Fig. 8 Quantitation of EPO amount in CSF, ipsilateral cortex and contralateral cortex in the ischemia-reperfusion model. EPO and EPOHBHAc were administered through carotid artery infusion at the onset of reperfusion. The CSF (A) and cortex (B) samples were collected $3 \mathrm{~h}$ after dosing, and the amount of EPO was measured by a human EPO ELISA kit. Data points marked with *,**, and *** indicate $p<0.05, p<0.01$, and $p<0.001$, respectively. All values are mean $\pm \mathrm{SD}(N=5)$

in this study to enhance the BBB permeability of EPO and, consequently, showed better therapeutic efficacy than unmodified EPO.

HBHAc is a short cationic peptide with the ability to transport macromolecules into cells without affecting the bioactivity of therapeutic cargos in our previous research [26, 40]. This is the first study to demonstrate that HBHAc can be used as a therapeutic protein carrier across the BBB. EPO-HBHAc showed a dose- and time-dependent cellular uptake in the brain endothelial cell model (Fig. 3), and elicited better transcytosis activity than unmodified EPO in the in vitro BBB model under both normal and damaged conditions, respectively (Fig. 5 and S3). Transcytosis is a unique phenomenon, and it exists in a different kind of cell, such as intestinal cells, osteoclasts, and endothelial cells. Endocytosis, intracellular vesicular trafficking, and exocytosis are the three typical steps of transcytosis. The first step might involve adsorptive(charge dependent) or receptor-mediated internalization [41]. Compared to native bovine albumin, cationized albumin showed better uptake in brain capillaries in vitro and in vivo. The distribution of anionic sites on brain endothelia might provide a good binding motif for the cationized proteins or peptides to bind through electrostatic interaction [42, 43]. EPO-HBHAc would undergo absorptive-mediated transcytosis, which is triggered by electrostatic interaction between poly-cations on HBHAc and anionic motifs on brain capillary endothelial cells [44-46]. Although the mechanism of transcytosis is still unclear, Rab GTPases might play an important role in targeting vesicles to the correct location and enabling exocytosis [47, 48]. Importantly, the intact EPO-HBHAc was detected by Western blotting, with the correct molecular weight, in the basolateral chamber of the in vitro BBB model (Fig. 5A), and this result indicates that EPOHBHAc could bypass endosomal degradation during transcytosis across the bEnd.3 monolayer.

In addition, the significantly higher erythropoiesis activity and neuroprotective activity in the EPO-HBHAc group compared with the EPO group (Figs. 6 and 7) could be related to the enhanced transcytosis ability of EPO-HBHAc in an in vitro BBB model. The higher amount of transported EPO-HBHAc was detected in the basolateral chamber than EPO (Fig. 5). Our in vitro results clearly illustrate that HBHAc modification could enhance the transcytosis ability EPO but not affect the erythropoiesis and neuroprotection bioactivities of EPO. Compared with EPO, EPO-HBHAc showed better efficacy in reducing infarct volume (Fig. 9). Thrombolysis and endovascular revascularization are the two common treatments for patients under ischemic stroke [49], and the
Fig. 9 The infarct volume evaluation in the ischemiareperfusion rat model. The brains were removed and stained with TTC reagent at $24 \mathrm{~h}$ after $3 \mathrm{VO}$. (A) The images of brain slices. (B) Infarct volumes (\% of contralateral side) were quantified. Data points marked with * and $* *$ indicate $p<0.05$ and $p<0.01$, respectively. All values are mean \pm SD. (Control: $N=6$; EPO: $N=5$; EPO-HBHAc: $N=5$ ) a

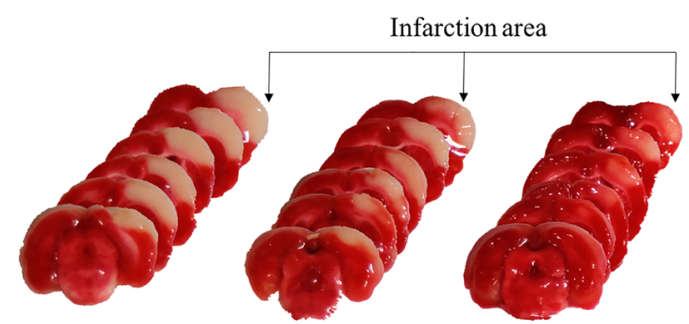

Control b

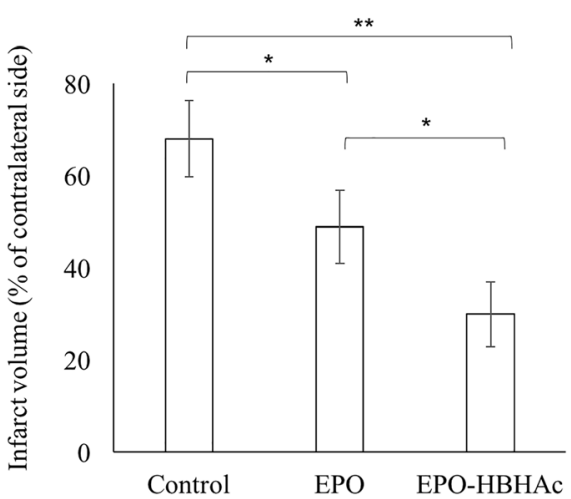


restoration of blood flow as soon as possible is important. However, the restoration of blood flow carries the risk of leading to reperfusion injury $[50,51]$, and to administer a neuroprotective agent at the onset of reperfusion may be a potential way to reduce reperfusion injury. Both EPO and EPO-HBHAc could significantly reduce the infarct volume by being administered at the onset of reperfusion, and these results are consistent with previous studies of EPO in neuroprotection [15]. Moreover, it has been reported that dysfunction of BBB occurred under ischemia-reperfusion conditions [52], and the unmodified EPO elicitation of the neuroprotective effect in vivo might be related to the disruption of BBB.

Evans blue dye is used to determine the time course of BBB permeability in the ischemia-reperfusion rat model. Evans blue could be detected within 1-2 h after reperfusion, and limited permeability of Evans blue was observed 22-24 h after reperfusion [53]. This previous research demonstrated that the disruption of BBB occurs within $2 \mathrm{~h}$ after reperfusion, and the disruption is then gradually alleviated. In our study, the $3 \mathrm{VO}$ rats were dosed at the onset of reperfusion, and the BBB may be disrupted at this time point. Herein, we suggested that the unmodified EPO might only cross via paracellular diffusion under leaky BBB conditions; in contrast, EPO-HBHAc could penetrate BBB not only through paracellular diffusion but also through the transcytosis pathway. The dual potential penetrating pathways mean that a higher EPO amount was detected in both CSF and cortex of the EPO-HBHAc group than of the unmodified EPO group in the ischemia-reperfusion model (Fig. 8). There was no detectable amount of EPO in the CSF and brain tissues in the control group, indicating that the human EPO ELISA kit did not show cross-reactivity with rat EPO. These results suggest that HBHAc could enhance delivery of EPO to the CNS in an ischemia-reperfusion model. Moreover, both EPO and EPOHBHAc did not worsen the BBB permeability in vitro and in vivo (Fig. 4 and Figure S7).

For the clinical application of EPO in stroke, EPO might be administered not only at the onset of reperfusion but also in the days following the ischemic insult. EPO-HBHAc elicited better penetrating ability not only in the damaged cortex (ipsilateral side) but also in the non-damaged cortex (contralateral side) as compared to EPO. Thus, we suggest that HBHAc modification might have the potential to deliver EPO to the $\mathrm{CNS}$ even as the BBB integrity is recovered after stroke. Due to the enhanced brain delivery effect of EPO-HBHAc, a lower dose might be administered to achieve its protective effect.

EPO is a low extravascular distribution protein [54], and HBHAc modification of EPO may enhance its tissue distribution. A statistically significant difference in the biodistribution of EPO and EPO-HBHAc in various organs was only found in the cortex, although there was a similar tendency in other tissues (Figure S6). This tissue-specific delivery phenomenon might be due to the following reasons. The carotid artery administration of EPO-HBHAc may increase the bioavailability of EPO in brain tissues. Besides, HBHAc with more positive charges in acidic conditions could enhance the penetrating ability [55]. Acidification of brain tissues under ischemic damage has been reported [56]. The $\mathrm{pH}$ value of the brain under normal condition is $7.24 \pm 0.07,6.43 \pm 0.13$ under ischemic condition [57]. Therefore, in the acidic brain region, EPO-HBHAc may be concentrated. This acid-induced enhancement of the penetrating ability did not occur in other organs under physiological $\mathrm{pH}$ conditions. Based on our published results of HBHAc, we did not find any specific receptor for HBHAc on the membrane of endothelium cells [55]. However, the mechanism that affects the distribution of EPO-HBHAc needs to be further studied.

To develop nonhematopoietic EPO mimetics is another approach to overcome the limitations of EPO therapy in CNS. Carbamylated EPO, asialo-erythropoietin, and EPO mimetic peptides showed neuroprotective effects while reducing the blood-stimulating side effects [58]. However, the multiple injections of not only EPO but also these derivatives might be used in further clinical applications of ischemic stroke and other CNS-related diseases. Thus, increasing the BBBpenetrating ability of these therapies is an effective and safe approach for EPO and EPO mimetics in further clinical use. HBHAc modifications could reduce the therapeutic dose and dosing frequency by improving the BBB permeability of EPO and these EPO derivatives.

This is the first proof-of-concept study to demonstrate that HBHAc modification could enhance the BBB penetration of EPO and improve the therapeutic effect, but it has potential limitations. First, it was difficult to differentiate whether the transported drugs passed through paracellular, damaged endothelium or intact endothelium both in vitro and in vivo, because the BBB disruption after ischemia-reperfusion is progressive. Both damaged and intact endothelia are presented during this situation. Second, to explore the alternative administration route of modified EPO, the intravenous administration of modified EPO should be considered. However, the intra-carotid arterial delivery of modified EPO is able to prove our concept that HBHAc modification could enhance the BBB permeability of EPO. Third, the dose-response relationship and the long-term efficacy studies of modified EPO are not thoroughly addressed in this study. Last, although the $3 \mathrm{VO}$ rat model could not completely mimic the complicated clinical condition of patients with ischemic stroke, it is able to demonstrate the concept that modified EPO could not only show better CNS delivery but also elicit better therapeutic efficacy. Moreover, in comparison with MCA occlusion only, the $3 \mathrm{VO}$ technique using the MCA and bilateral CCAs produces a consistent cortical injury [59]. Thus, the $3 \mathrm{VO}$ rat model was selected to investigate the in vivo efficacy and distribution in this 
study. Together, to explore the flexible clinical applications of modified EPO, the studies of the possibilities of intravenous route for administration, long-term efficacy, and dose-response relationship, as well as the investigation of therapeutic efficacy using other ischemiareperfusion models of modified EPO are crucial for further investigation of EPO-HBHAc in the future.

\section{Conclusion}

In summary, we successfully produced recombinant EPO and EPO-HBHAc with high purity and erythropoiesis activity from a mammalian cell culture model. EPO-HBHAc elicited higher cellular uptake ability than EPO and showed time- and dose-dependent cellular uptake in brain endothelial cells. Moreover, EPO-HBHAc also had a greater ability to penetrate an in vitro BBB model, and erythropoiesis activity and neuroprotective activity were both maintained. EPO-HBHAc also demonstrated effectively enhanced BBB-penetrating ability and therapeutic efficacy in vivo in an ischemia-reperfusion rat model. Therefore, EPO-HBHAc could be a potential therapeutic agent for the well-known reperfusion injury in patients undergoing ischemic stroke and could improve the therapeutic outcome. Furthermore, HBHAc may be a potential carrier for brain delivery, and it might have promising further applications in other CNS-related diseases.

Acknowledgments We thank Dr. Lih-Ching Hsu for providing CHO-K1 cells. We thank Dr. Yu-Li Lo for providing bEnd. 3 cells and CTX TNA2 cells. This work was supported by a grant to Li-Jiuan Shen from the Ministry of Science and Technology, Taiwan (MOST 105-2320-B-002018-MY3). Po-Chuan Chiu was supported by a scholarship from the XinChen Medical Research Foundation, Taiwan.

Funding Information This study was financially supported by the Ministry of Science and Technology, Taiwan (MOST 105-2320-B-002018-MY3).

\section{Compliance with Ethical Standards}

Conflict of Interest The authors declare that they have no competing interests.

Abbreviations $\mathrm{BBB}$, blood-brain barrier; CCAs, common carotid arteries; CNS, central nervous system; CPP, cell-penetrating peptide; EPO, erythropoietin; MCA, middle cerebral artery; NMDA, N-methyl-D-aspartate; rADI, recombinant arginine deiminase; TEER, transepithelial electrical resistance; TTC, 2,3,5-triphenyltetrazolium chloride; 3VO, 3 vessels occlusion

\section{References}

1. Organization WH. Global health estimates 2016: Disease burden by cause, age, sex, by country and by region, 2000-2016. 2018.
2. Jean WC, Spellman SR, Nussbaum ES, Low WC. Reperfusion injury after focal cerebral ischemia: The role of inflammation and the therapeutic horizon. Neurosurgery. 1998;43:1382-96.

3. Zhang RL, Chopp M, Chen H, Garcia JH. Temporal profile of ischemic tissue-damage, neutrophil response, and vascular plugging following permanent and transient $(2 \mathrm{~h})$ middle cerebralartery occlusion in the rat. Journal of the Neurological Sciences. 1994;125:3-10.

4. Warach S, Latour LL. Evidence of reperfusion injury, exacerbated by thrombolytic therapy, in human focal brain ischemia using a novel imaging marker of early blood-brain barrier disruption. Stroke. 2004;35:2659-61.

5. Gauberti M, Lapergue B, de Lizarrondo SM, Vivien D, Richard S, Bracard S, et al. Ischemia-reperfusion injury after endovascular thrombectomy for ischemic stroke. Stroke. 2018;49:3071-4.

6. Buemi M, Cavallaro E, Floccari E, Sturiale A, Aloisi C, Trimarchi $\mathrm{M}$, et al. The pleiotropic effects of erythropoietin in the central nervous system. Journal of Neuropathology and Experimental Neurology. 2003;62:228-36.

7. Fisher JW. Erythropoietin: Physiology and pharmacology update. Experimental Biology and Medicine. 2003;228:1-14.

8. Ott C, Martens H, Hassouna I, Oliveira B, Erck C, Zafeiriou MP, et al. Widespread expression of erythropoietin receptor in brain and its induction by injury. Molecular Medicine. 2015;21:803-15.

9. Brines M, Cerami A. Emerging biological roles for erythropoietin in the nervous system. Nature Reviews Neuroscience. 2005;6:48494.

10. Genc S, Koroglu TF, Genc K. Erythropoietin and the nervous system. Brain Research. 2004;1000:19-31.

11. Marti HH. Erythropoietin and the hypoxic brain. Journal of Experimental Biology. 2004;207:3233-42.

12. Marti HH, Wenger RH, Rivas LA, Straumann U, Digicaylioglu M, Henn V, et al. Erythropoietin gene expression in human, monkey and murine brain. European Journal of Neuroscience. 1996;8:66676.

13. Brines ML, Ghezzi P, Keenan S, Agnello D, de Lanerolle NC, Cerami C, et al. Erythropoietin crosses the blood-brain barrier to protect against experimental brain injury. Proceedings of the National Academy of Sciences of the United States of America. 2000;97.

14. Wang Y, Zhang ZG, Rhodes K, Renzi M, Zhang RL, Kapke A, et al. Post-ischemic treatment with erythropoietin or carbamylated erythropoietin reduces infarction and improves neurological outcome in a rat model of focal cerebral ischemia. British Journal of Pharmacology. 2007;151:1377-84.

15. Jiang CJ, Xu Q, Xu K, Dai HY, Zhang ZY, Wu WJ, et al. Effects of erythropoietin on stat1 and stat 3 levels following cerebral ischemiareperfusion in rats. International Journal of Neuroscience. 2013;123:684-90.

16. Yu YP, Xu QQ, Zhang Q, Zhang WP, Zhang LH, Wei EQ. Intranasal recombinant human erythropoietin protects rats against focal cerebral ischemia. Neuroscience Letters. 2005;387:5-10.

17. Ehrenreich H, Hasselblatt M, Dembowski C, Cepek L, Lewczuk P, Stiefel M, et al. Erythropoietin therapy for acute stroke is both safe and beneficial. Molecular Medicine. 2002;8:495-505.

18. Provenzano R, Bhaduri S, Singh AK, Grp PS. Extended epoetin alfa dosing as maintenance treatment for the anemia of chronic kidney disease: The prompt study. Clinical Nephrology. 2005;64: 113-23.

19. Roche. Product information: Neorecormon subcutaneous injection solution, intravenous injection solution, epoetin beta subcutaneous injection solution, intravenous injection solution. 2012.

20. Ehrenreich H, Weissenborn K, Prange H, Schneider D, Weimar C, Wartenberg $\mathrm{K}$, et al. Recombinant human erythropoietin in the treatment of acute ischemic stroke. Stroke. 2009;40:E647-E56. 
21. Pardridge WM. The blood-brain barrier: Bottleneck in brain drug development. The Journal of the American Society for Experimental NeuroTherapeutics. 2005;2:3-14.

22. Kabanov AV, Batrakova EV. New technologies for drug delivery across the blood brain barrier. Current Pharmaceutical Design. 2004;10:1355-63.

23. Misra A, Ganesh S, Shahiwala A, Shah SP. Drug delivery to the central nervous system: A review. Journal of Pharmacy and Pharmaceutical Sciences. 2003;6:252-73.

24. Reddy JS, Venkateswarlu V. Novel delivery systems for drug targeting to the brain. Drugs of the Future. 2004;29:36-44.

25. Guidotti G, Brambilla L, Rossi D. Cell-penetrating peptides: From basic research to clinics. Trends in Pharmacological Sciences. 2017;38:406-24.

26. Wu F-LL, Yeh T-H, Chen Y-L, Chiu Y-C, Cheng J-C, Wei M-F, et al. Intracellular delivery of recombinant arginine deiminase (radi) by heparin-binding hemagglutinin adhesion peptide restores sensitivity in radi-resistant cancer cells. Molecular Pharmaceutics. 2014;11:2777-86.

27. Yeh TH, Chen YR, Chen SY, Shen WC, Ann DK, Zaro JL, et al. Selective intracellular delivery of recombinant arginine deiminase (adi) using ph-sensitive cell penetrating peptides to overcome adi resistance in hypoxic breast cancer cells. Mol Pharm. 2015.

28. Jain SK, Paul-Satyaseela M, Lamichhane G, Kim KS, Bishai WR. Mycobacterium tuberculosis invasion and traversal across an in vitro human blood-brain barrier as a pathogenic mechanism for central nervous system tuberculosis. Journal of Infectious Diseases. 2006;193:1287-95.

29. Menozzi FD, Reddy VM, Cayet D, Raze D, Debrie AS, Dehouck MP, et al. Mycobacterium tuberculosis heparin-binding haemagglutinin adhesin (hbha) triggers receptor-mediated transcytosis without altering the integrity of tight junctions. Microbes and Infection. 2006;8:1-9.

30. Dando SJ, Mackay-Sim A, Norton R, Currie BJ, St John JA, Ekberg JAK, et al. Pathogens penetrating the central nervous system: Infection pathways and the cellular and molecular mechanisms of invasion. Clinical Microbiology Reviews. 2014;27:691-726.

31. Burrill DR, Vernet A, Collins JJ, Silver PA, Way JC. Targeted erythropoietin selectively stimulates red blood cell expansion in vivo. Proceedings of the National Academy of Sciences of the United States of America. 2016;113:5245-50.

32. Helms HC, Abbott NJ, Burek M, Cecchelli R, Couraud PO, Deli $\mathrm{MA}$, et al. In vitro models of the blood-brain barrier: An overview of commonly used brain endothelial cell culture models and guidelines for their use. Journal of Cerebral Blood Flow and Metabolism. 2016;36:862-90.

33. Souvenir R, Doycheva D, Zhang JH, Tang JP. Erythropoietin in stroke therapy: Friend or foe. Current Medicinal Chemistry. 2015;22:1205-13.

34. Stalmans S, Bracke N, Wynendaele E, Gevaert B, Peremans K, Burvenich $\mathrm{C}$, et al. Cell-penetrating peptides selectively cross the blood-brain barrier in vivo. Plos One. 2015;10.

35. Zou LL, Ma JL, Wang T, Yang TB, Liu CB. Cell-penetrating peptide-mediated therapeutic molecule delivery into the central nervous system. Current Neuropharmacology. 2013;11:197-208.

36. Alcala-Barraza SR, Lee MS, Hanson LR, McDonald AA, Frey WH, McLoon LK. Intranasal delivery of neurotrophic factors bdnf, cntf, epo, and nt-4 to the cns. Journal of Drug Targeting. 2010;18: 179-90.

37. Boado RJ, Hui EKW, Lu JZ, Pardridge WM. Drug targeting of erythropoietin across the primate blood-brain barrier with an igg molecular trojan horse. Journal of Pharmacology and Experimental Therapeutics. 2010;333:961-9.
38. Zhang F, Xing J, Liou AKF, Wang S, Gan Y, Luo YM, et al. Enhanced delivery of erythropoietin across the blood-brain barrier for neuroprotection against ischemic neuronal injury. Translational Stroke Research. 2010;1:113-21.

39. Wu SK, Yang MT, Kang KH, Liou HC, Lu DH, Fu WM, et al. Targeted delivery of erythropoietin by transcranial focused ultrasound for neuroprotection against ischemia/reperfusion-induced neuronal injury: A long-term and short-term study. Plos One. 2014;9.

40. Yeh TH, Chen YR, Chen SY, Shen WC, Ann DK, Zaro JL, et al. Selective intracellular delivery of recombinant arginine deiminase (adi) using ph-sensitive cell penetrating peptides to overcome adi resistance in hypoxic breast cancer cells. Molecular Pharmaceutics. 2016;13:262-71.

41. Jane E. Preston, N. Joan Abbott, Begley DJ. Chapter five transcytosis of macromolecules at the blood-brain barrier. Advances in Pharmacology. 2014;71:17.

42. Bush MS, Allt G. Blood nerve barrier-distribution of anionic sites on the endothelial plasma-membrane and basal lamina. Brain Research. 1990;535:181-8.

43. Dossantos WLC, Rahman J, Klein N, Male DK. Distribution and analysis of surface-charge on brain endothelium in-vitro and in-situ. Acta Neuropathologica. 1995;90:305-11.

44. Herve F, Ghinea N, Scherrmann JM. Cns delivery via adsorptive transcytosis. Aaps Journal. 2008;10:455-72.

45. Lu W. Adsorptive-mediated brain delivery systems. Current Pharmaceutical Biotechnology. 2012;13:2340-8.

46. Kumagai AK, Eisenberg JB, Pardridge WM. Absorptive-mediated endocytosis of cationized albumin and a beta-endorphin-cationized albumin chimeric peptide by isolated brain capillaries - model system of blood-brain-barrier transport. Journal of Biological Chemistry. 1987;262:15214-9.

47. Rajendran L, Knolker HJ, Simons K. Subcellular targeting strategies for drug design and delivery. Nature Reviews Drug Discovery. 2010;9:29-42.

48. Nayak RC, Keshava S, Esmon CT, Pendurthi UR, Rao LVM. Rab gtpases regulate endothelial cell protein c receptor-mediated endocytosis and trafficking of factor viia. Plos One. 2013;8.

49. Catanese L, Tarsia J, Fisher M. Acute ischemic stroke therapy overview. Circulation Research. 2017;120:541-58.

50. Brott T, Broderick J, Kothari R, Odonoghue M, Barsan W, Tomsick $\mathrm{T}$, et al. Intracerebral hemorrhage after intravenous t-pa therapy for ischemic stroke. Stroke. 1997;28:2109-18.

51. Pan J, Konstas AA, Bateman B, Ortolano GA, Pile-Spellman J. Reperfusion injury following cerebral ischemia: Pathophysiology, $\mathrm{mr}$ imaging, and potential therapies. Neuroradiology. 2007;49:93102.

52. Abdullahi W, Tripathi D, Ronaldson PT. Blood-brain barrier dysfunction in ischemic stroke: Targeting tight junctions and transporters for vascular protection. American Journal of PhysiologyCell Physiology. 2018;315:C343-C56.

53. Belayev L, Busto R, Zhao WZ, Ginsberg MD. Quantitative evaluation of blood-brain barrier permeability following middle cerebral artery occlusion in rats. Brain Research. 1996;739:88-96.

54. Halstenson CE, Macres M, Katz SA, Schnieders JR, Watanabe M, Sobota JT, et al. Comparative pharmacokinetics and pharmacodynamics of epoetin-alfa and epoetin-beta. Clinical Pharmacology \& Therapeutics. 1991;50:702-12.

55. Po-Chuan Chiu, Pei-Yu Hsieh, Jyun-wei Kang, Po-Hsun Chang, Shen L-J. Study of the intracellular delivery mechanism of a phsensitive peptide modified with enhanced green fluorescent protein. Journal of Drug Targeting. 2019. 
56. Kalimo H, Rehncrona S, Soderfeldt B, Olsson Y, Siesjo BK. Brain lactic-acidosis and ischemic cell-damage. Journal of Cerebral Blood Flow and Metabolism. 1981;1:313-27.

57. Nedergaard M, Kraig RP, Tanabe J, Pulsinelli WA. Dynamics of interstitial and intracellular ph in evolving brain infarct. American Journal of Physiology. 1991;260:R581-R8.

58. Subiros N, del Barco DG, Coro-Antich RM. Erythropoietin: Still on the neuroprotection road. Therapeutic Advances in Neurological Disorders. 2012;5:161-73.
59. Yamamoto H, Nagata I, Niitsu Y, Xue JH, Zhang ZW, Kikuchi H. Evaluation of mcao stroke models in normotensive rats: Standardized neocortical infarction by the 3 vo technique. Experimental Neurology. 2003;182:261-74.

Publisher's Note Springer Nature remains neutral with regard to jurisdictional claims in published maps and institutional affiliations. 